\title{
An index for estimating the potential metal pollution contribution to atmospheric particulate matter from road dust in Beijing
}

\author{
Hongtao Zhao ${ }^{a}$, Yaping Shao ${ }^{b}$, Chengqing Yin ${ }^{c}$, Yan Jiang ${ }^{a}$, Xuyong Li ${ }^{\mathrm{a}, *}$ \\ a State Key Laboratory of Urban and Regional Ecology, Research Center for Eco-Environmental Sciences, Chinese Academy of Sciences, 18 Shuangqing Road, Beijing 100085, China \\ b Institute for Geophysics and Meteorology, University of Cologne, Cologne 50923, Germany \\ ' State Key Laboratory of Environmental Aquatic Chemistry, Research Center for Eco-Environmental Sciences, Chinese Academy of Sciences, 18 Shuangqing Road, Beijing 100085, China
}

\section{H I G H L I G H T S}

- An innovative road dust index was developed.

- Road dust characteristics were ranked and weighted in the index model.

- Source and transport factors were both considered in the index model.

- The index can indicate risks of road dust causing atmospheric particulate pollution.

\section{A R T I C L E I N F O}

\section{Article history:}

Received 17 September 2015

Received in revised form 18 January 2016

Accepted 18 January 2016

Available online 24 January 2016

Editor: D. Barcelo

\section{Keywords:}

Road dust particle

Risk assessment methods

Metal pollution

Urban-rural gradient

Atmospheric particulate pollution

\section{G R A P H I C A L A B S T R A C T}

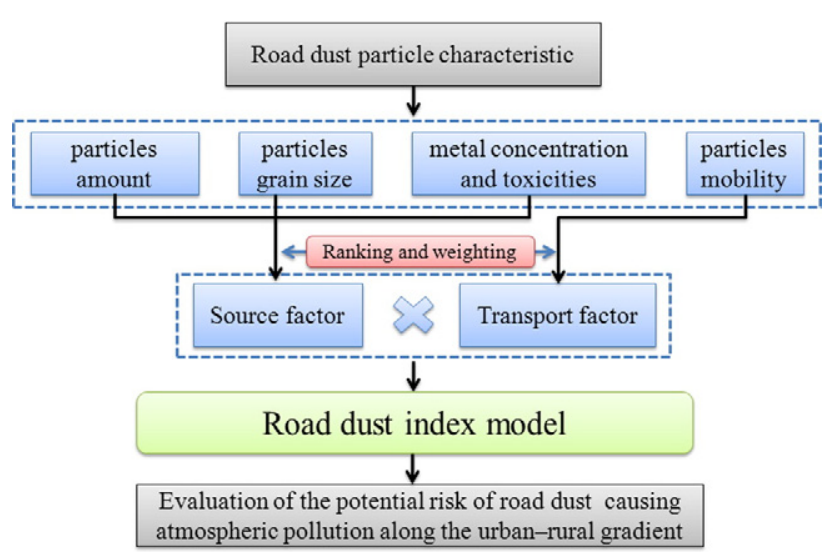

\section{A B S T R A C T}

The resuspension of road dust from street surfaces could be a big contributor to atmospheric particulate pollution in the rapid urbanization context in the world. However, to date what its potential contribution to the spatial pattern is little known. Here we developed an innovative index model called the road dust index $\left(R I_{<105 \mu \mathrm{m}}\right)$ and it combines source and transport factors for road dust particles $<105 \mu \mathrm{m}$ in diameter. It could quantify and differentiate the impact of the spatial distribution of the potential risks posed by metals associated with road dust on atmospheric suspended particles. The factors were ranked and weighted based on road dust characteristics (the amounts, grain sizes, and mobilities of the road dust, and the concentrations and toxicities of metals in the road dust). We then applied the $R I_{<105 \mu \mathrm{m}}$ in the Beijing region to assess the spatial distribution of the potential risks posed by metals associated with road dust on atmospheric suspended particles. The results demonstrated that the road dust in urban areas has higher potential risk of metal to atmospheric particles than that in rural areas. The $R I_{<105 \mu \mathrm{m}}$ method offers a new and useful tool for assessing the potential risks posed by metals associated with road dust on atmospheric suspended particles and for controlling atmospheric particulate pollution caused by road dust emissions.

\footnotetext{
* Corresponding author.

E-mail address: xyli@rcees.ac.cn (X. Li).
} 
Table 1

Characteristics of administrative divisions along the urban-rural gradient.

\begin{tabular}{|c|c|c|c|c|c|}
\hline $\begin{array}{l}\text { Area } \\
{\text { (no. of sampling sites })^{a}}\end{array}$ & $\begin{array}{l}\text { Population density } \\
\left(\text { persons } / \mathrm{km}^{2}\right)^{\mathrm{b}}\end{array}$ & $\begin{array}{l}\text { Average daily traffic } \\
(\text { vehicles / }(\mathrm{d} \mathrm{m}))^{\mathrm{c}}\end{array}$ & $\begin{array}{l}\text { Total energy consumption } \\
(1000 \text { t of SCE })^{d}\end{array}$ & $\begin{array}{l}\text { Street cleaning } \\
\text { method }^{\mathrm{e}}\end{array}$ & $\begin{array}{l}\text { Frequency of sweeping } \\
(\text { times } / \mathrm{d})^{\mathrm{f}}\end{array}$ \\
\hline UCA (15) & 15,000 & 8900 & 960 & M & 3 \\
\hline UVA (10) & 1200 & 115 & 346 & $\mathrm{H}$ & $<0.2$ \\
\hline CSA (58) & $3000-5000$ & 6700 & 960 & M & $3-2$ \\
\hline RTA (41) & $1500-2000$ & 1300 & 346 & $\mathrm{H}$ & 2 \\
\hline RVA (40) & 1000 & 105 & 346 & $\mathrm{H}$ & 0.3 \\
\hline
\end{tabular}

${ }^{\text {a }}$ UCA = central urban area; UVA = urban village area; CSA = central suburban county area; RTA = rural town area; RVA = rural village area.

b Population density was estimated using data from the Beijing Municipal Bureau of Statistics.

c Average daily traffic was estimated using data from Beijing Transportation Research. Each value was divided by the number of lanes in the road to allow different sites to be compared.

d Energy consumption refers to residential consumption, including of coal, gasoline, diesel oil, liquefied petroleum gas, natural gas, heat, and electricity. Total energy consumption was estimated using data from the Beijing Municipal Bureau of Statistics. SCE means standard coal energy. SCE data were available only for the categories "urban" and "rural".

e $\mathrm{M}=$ mechanical sweeper; $\mathrm{H}=$ hand-swept using straw brooms. Most sites on the main roads were paved with asphalt, but a few roads in the rural areas were paved with concrete.

f Street cleaning methods and frequencies were determined from our own investigations.

\section{Introduction}

At present, air quality degradation due to ambient particulate matter has become an environmental issue of public health concern in most metropolitan areas in China (Chen et al., 2012; Huang et al., 2014). It is well known that the resuspension of road dust particles from urban street surfaces is an important source of atmospheric particulate pollution (Amato et al., 2009b; Martuzevicius et al., 2011). Previous studies indicated that road dust particles, with diameters of less than $100 \mu \mathrm{m}$, can easily be resuspended by passing traffic or the wind, and that some of the particles can subsequently be redeposited on roads (Rogge et al., 1993; Zhao et al., 2014b). Road dust particles have been found to be an important contributor to $\mathrm{PM}_{10}$ and $\mathrm{PM}_{2.5}$, respectively (Amato et al., 2009a; Bukowiecki et al., 2010; Karanasiou et al., 2011; Kuhns et al., 2001).

Furthermore, rapid urban population growth and industrialization in China produce large quantities of particulate matter and contribute to the particulate-bound pollutant contents of road dust (Zhao et al., 2011). The emission magnitudes between urban and rural areas could be different. However, there is still no method to assess the spatial distribution of the potential risks posed by metals associated with road dust particles. A variety of road dust particle

(a)

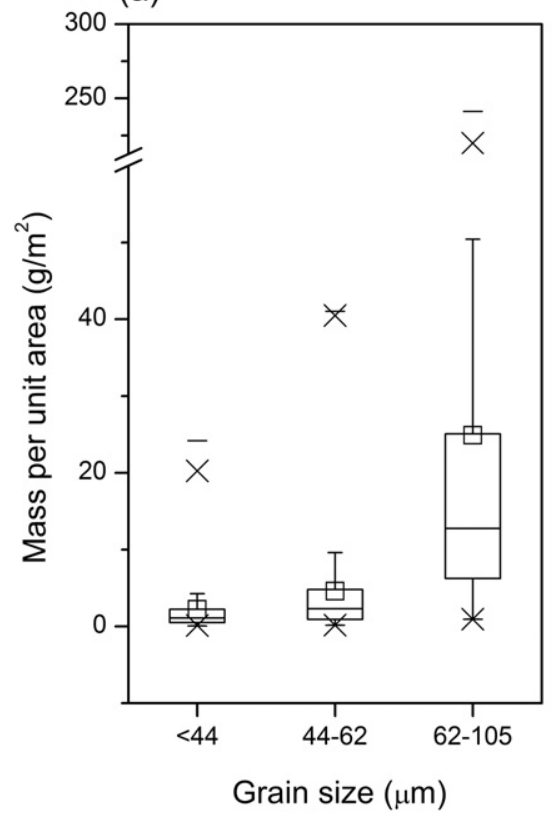

emission models, such as AP-42 (US-EPA, 2011), PMF (Bukowiecki et al., 2010; Karanasiou et al., 2011) and TRAKER (Etyemezian et al., 2003; Kuhns et al., 2001), have been developed in recent years to quantify the resuspension of road dust to become suspended particles in the atmosphere, yet these studies are mostly from the perspective of air particles. It is difficult to use such models to assess the risk of road dust particles becoming atmospheric particulate matter because the models require measurement of many parameters (e.g., very detailed traffic condition parameters).

There is a clear need to design a new method for simplicity and ease of use to identify the potential risk of road dust becoming atmospheric particulate matter. Furthermore, little information is available on spatial and temporal variations in potential emission sources, and on the mechanisms through which road dust particles are resuspended. Thus, the present study aims to 1 ) investigate the spatial pattern of road dust particle characteristics (e.g., the amount, grain size, mobility, and metal concentrations) along an urban-rural gradient; 2) develop an innovative index model combining the source and transport factor with consideration of the road dust characteristics; and 3) to quantify and differentiate the impact of the spatial distribution of the potential risks posed by metals associated with road dust on atmospheric suspended particles.

(b)

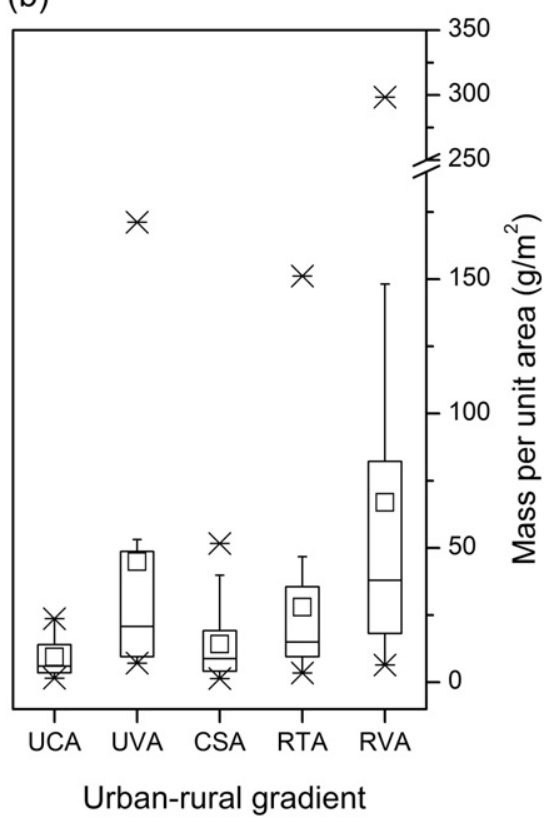

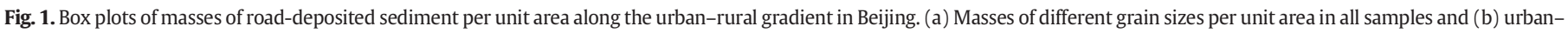

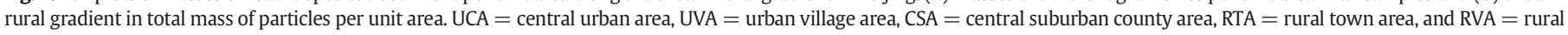
village area. 


\section{Materials and methods}

\subsection{Study area and road dust sampling}

In general, a big city in China has a division by the government along urban, suburban, and rural areas as follows: urban district, suburban county, rural township, rural village and urban village. Our RDS samples were collected from a typical area of each of the administrative division units in the Beijing metropolitan region. The Beijing metropolitan region includes 16 administrative sub-divisions, which are county-level units governed directly by the municipality. There are six districts in the urban area, and eight districts and two counties in the suburban area. The whole region can be divided into urban, suburban and rural areas. In suburban and rural areas, each county consists of a group of towns, and each town consists of a group of villages. We established five sampling areas along the urban-suburban-rural gradient, including in the central urban (UCA), urban village (UVA), central suburban county (CSA), rural town (RTA), and rural village areas (RVA). The series of units UCA, CSA, RTA, RVA and UVA has the urban-rural gradient feature with gradient variation of several important characteristics of different administrative divisions, such as population density, average daily traffic, total energy consumption, street cleaning method and frequency. In general, population density, traffic density, energy consumption, and frequency of sweeping decreased along the urban-rural gradient, as shown in Table 1 (Zhao and Li, 2013). Additionally, UCA and CSA have relatively smooth and less damaged impervious surfaces, and regularly daily mechanical sweeping; RTA, RVA and UVA have heavily damaged imperious surfaces, and rarely street sweeping. Our RDS samples were collected from a typical area of each of the administrative division units in the Beijing metropolitan region. In this study, we focused on

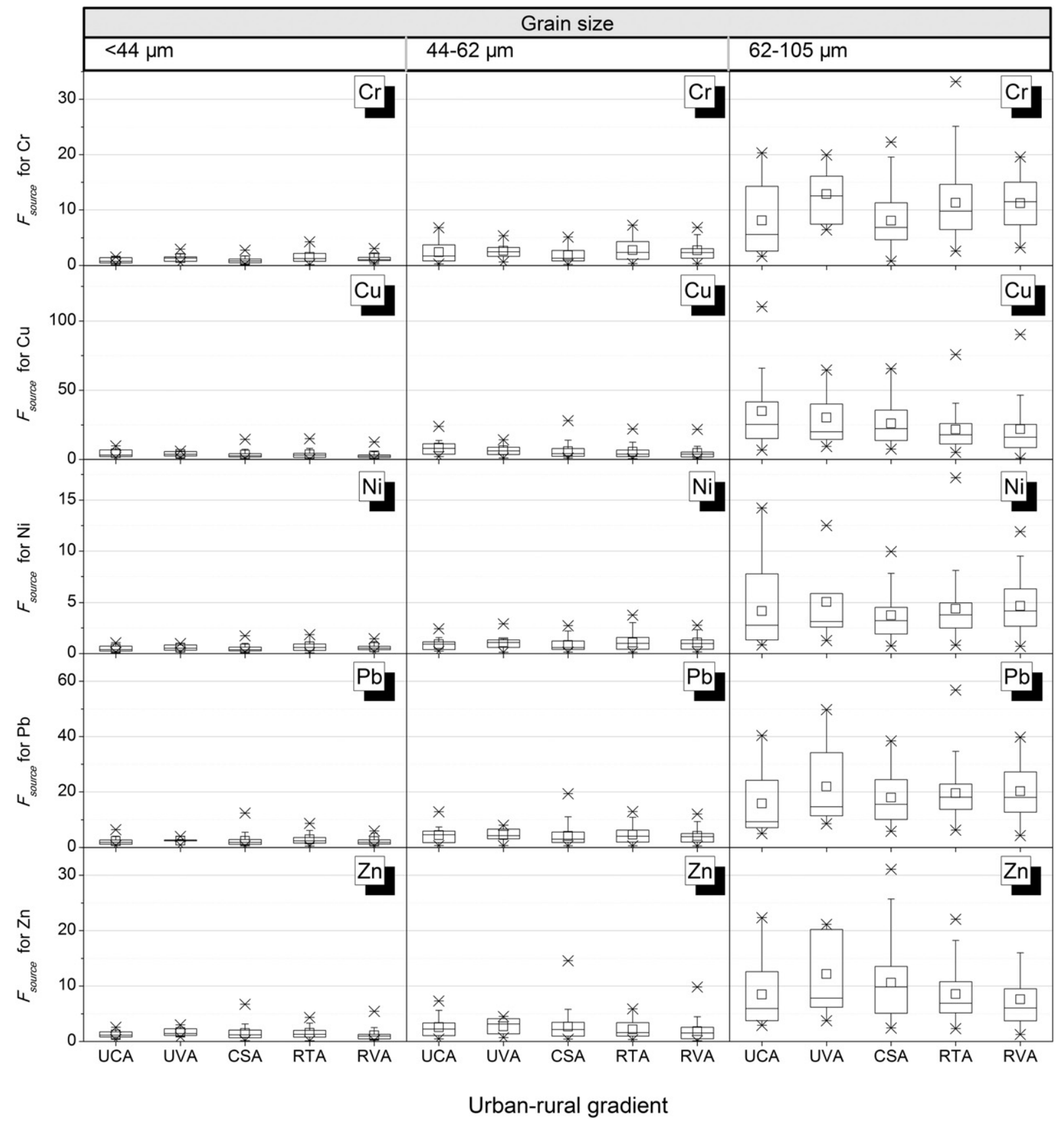

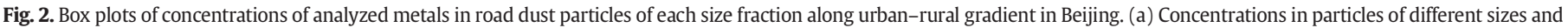

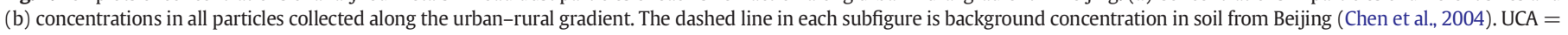
central urban area, UVA $=$ urban village area, CSA $=$ central suburban county area, $\mathrm{RTA}=$ rural town area, and RVA $=$ rural village area. 
Table 2

Levels $\left(M_{\text {weighted }}\right)$ defined for amounts of road dust, and number of sampling sites with each road dust level in each area.

\begin{tabular}{|c|c|c|c|c|c|c|c|}
\hline \multirow[t]{2}{*}{ Level of road dust present } & & \multicolumn{6}{|c|}{$M_{\text {weighted }}$ level } \\
\hline & & I & II & III & IV & $\mathrm{V}$ & VI \\
\hline Amount of road dust present $\left(\mathrm{g} / \mathrm{m}^{2}\right)^{\mathrm{a}}$ & & $0-5$ & $5.1-10.0$ & $10.1-20.0$ & $20.1-40.0$ & $40.1-80.0$ & $>80$ \\
\hline$M_{\text {weighted }}$ value & & 1.0 & 2.0 & 3.0 & 4.0 & 5.0 & 6.0 \\
\hline \multirow[t]{5}{*}{ Number of sampling sites in each area ${ }^{\mathrm{b}}$} & UCA & $6(40 \%)^{\mathrm{a}}$ & $3(20 \%)$ & $4(27 \%)$ & $2(13 \%)$ & $0(0 \%)$ & $0(0 \%)$ \\
\hline & CSA & $15(26 \%)$ & $15(26 \%)$ & $15(26 \%)$ & $9(16 \%)$ & $4(7 \%)$ & $0(0 \%)$ \\
\hline & RTA & $3(7 \%)$ & $7(17 \%)$ & $14(34 \%)$ & $8(20 \%)$ & $5(12 \%)$ & $4(10 \%)$ \\
\hline & RVA & $1(3 \%)$ & $2(5 \%)$ & $7(18 \%)$ & $14(35 \%)$ & $5(13 \%)$ & $11(28 \%)$ \\
\hline & UVA & $0(0 \%)$ & $3(30 \%)$ & $0(0 \%)$ & $4(40 \%)$ & $2(20 \%)$ & $1(10 \%)$ \\
\hline Total & & 25 (15\%) & $30(18 \%)$ & 40 (24\%) & 37 (23\%) & $16(10 \%)$ & $16(10 \%)$ \\
\hline
\end{tabular}

a Refer to Fig. 1(b).

$\mathrm{b}$ The percentage of the total number of sampling sites is shown in parentheses.

the main traffic road in each administration division unit along the urban-rural gradient. Road dust samples were collected using a domestic vacuum cleaner (Philips FC8264) between September 2 and 10, 2009 , which followed a dry period of about two weeks. The vacuum cleaner was very efficient and had an air filtration system and cyclonic dustbin that effectively captured microscopic particulates. Three sampling sites were selected in each of the study areas. An unspecified area at each site was vacuumed from the central road marking to the curb until a reasonable amount of RDS was collected, and then the size of the area sampled was measured with a ruler. Each RDS sample was weighed with an electronic balance, and sample masses of $0.8-1.5 \mathrm{~kg}$ were found to have been collected at each site.

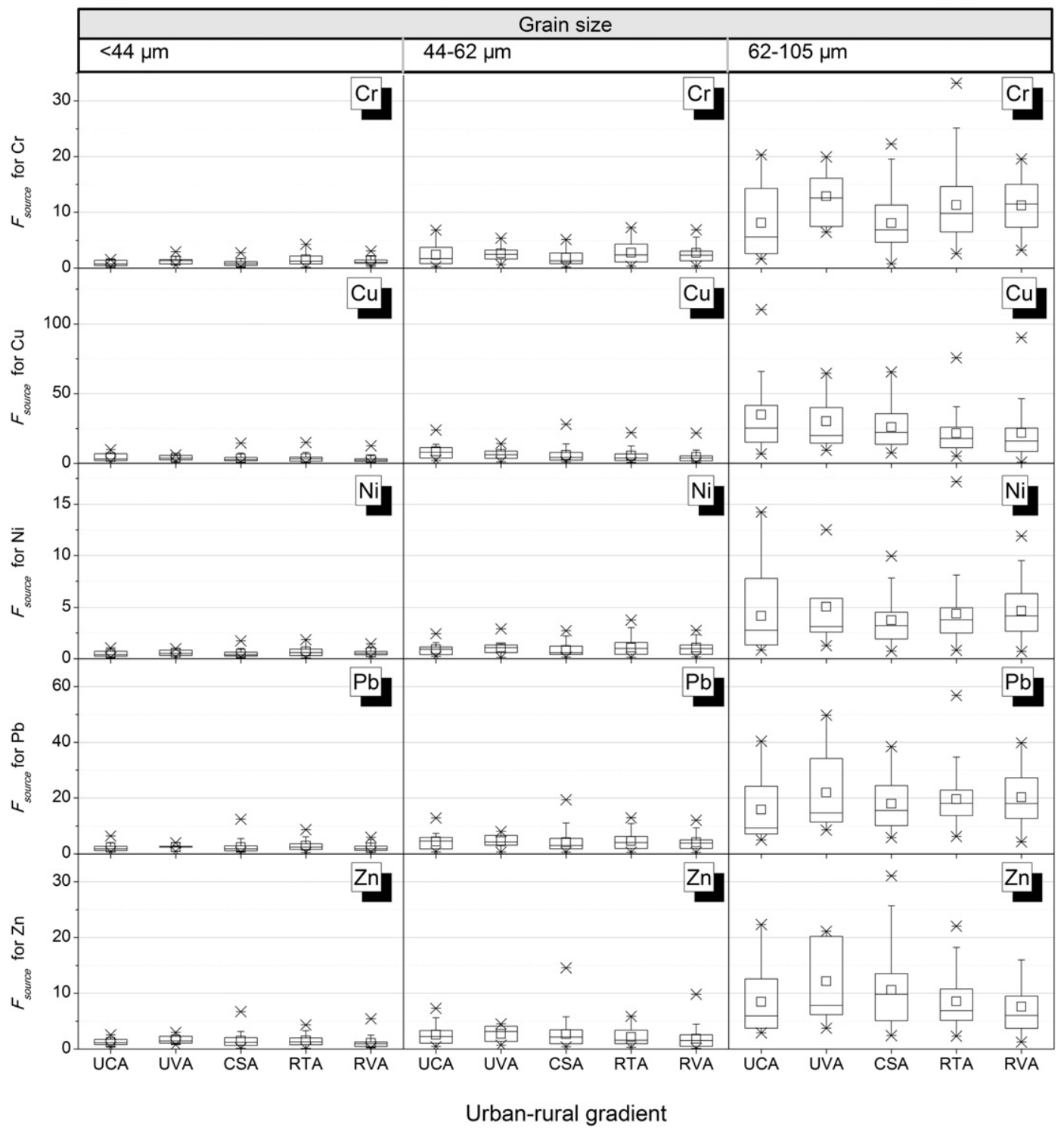

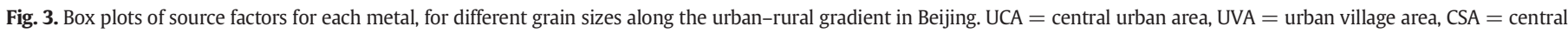
suburban county area, RTA = rural town area, and RVA = rural village area. 
Each sample was fractionated into grain sizes $<44,44-62$, and $62-105 \mu \mathrm{m}$ using polyester sieves. The $>105 \mu \mathrm{m}$ fraction was discarded. It has been found in many studies that particles $<100 \mu \mathrm{m}$ in diameter are important contributors to atmospheric PM in urban areas, because they can easily be suspended and resuspended (Charlesworth et al., 2011; Miguel et al., 1999; Sabin et al., 2006). Cr, Cu, Ni, Pb, and Zn concentrations for each grain size fraction were determined.

\subsection{Analytical methods and quality control}

Total $\mathrm{Cr}, \mathrm{Cu}, \mathrm{Ni}, \mathrm{Pb}$, and $\mathrm{Zn}$ concentrations in each sample were determined using an Elan 6000 inductively coupled plasma-optical emission spectroscopy instrument (Perkin-Elmer, Waltham, MA, USA) after the sample had been digested in a mixture of $\mathrm{HF}$ and $\mathrm{HClO}_{4}$ on a hotplate (Tessier et al., 1979). Certified geochemical soil reference materials (CRMs) GSS-1 and GSS-2 were also analyzed to provide quality assurance and quality control $(\mathrm{QA} / \mathrm{QC})$ information. The analytical methods and quality control procedures have been described in detail (Zhao et al., 2014a).

\subsection{Building the road dust index used to evaluate potential contributions of road dust to atmospheric particulate pollution}

No index models have specifically been designed to identify the potential risk of road dust becoming atmospheric particulate matter. We therefore developed a road dust index model based on principles of the phosphorus index (Gburek et al., 2000; Heathwaite et al., 2005; Sharpley et al., 2008), which is used to rank risks from diffuse agricultural pollution. The road dust index combines source and transport factors

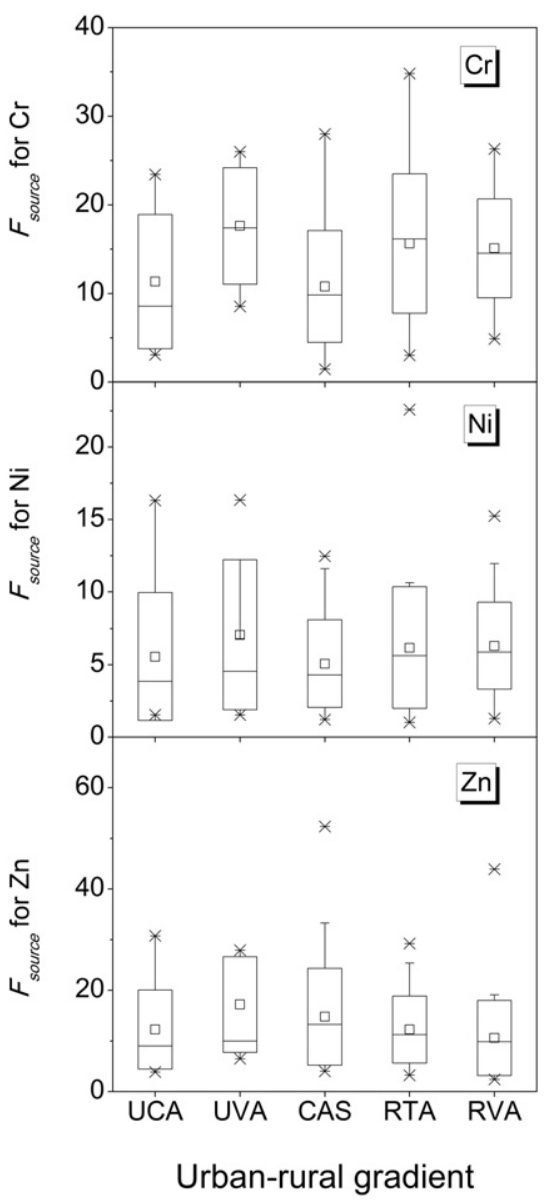

and can be used to identify critical source areas by quantifying relative pollution risks, allowing the risks posed by metals associated with road dust to be assessed. The road dust index $\left(R I_{<105 \mu \mathrm{m}}\right)$ takes into account metal concentrations in the particles and the amounts and mobilities of the road dust particles, and was calculated via

$R I_{<105 \mu \mathrm{m}}=F_{\text {source }} \times F_{\text {transport }}$,

where $F_{\text {source }}$ and $F_{\text {transport }}$ are road dust source and transport factors, respectively.

\subsubsection{Calculating the source factor}

The source factor used in the road dust index model considers the amount of road dust present, grain sizes, and amounts and types of pollutants associated with the road dust particles. The source factor was calculated using Eq. (2). We used measurements made at a large number (164) of sites along the urban-rural gradient to give the best possible estimates for the road dust parameters. The mass of road dust per unit area varied widely, with range $1.6-306.5 \mathrm{~g} / \mathrm{m}^{2}$ and mean $31.8 \mathrm{~g} / \mathrm{m}^{2}$. Metal concentrations in each road dust grain size fraction were measured.

$F_{\text {source }}=\sum_{j}^{m} \sum_{i}^{n}\left(T_{r}{ }^{i} \times \frac{C_{i j}}{C_{r i}} \times P j \times M_{\text {weighted }}\right)$.

In Eq. (2), $T_{r}^{i}$ is the toxic response factor for the metal of interest (in increasing order, $\mathrm{Zn}=1, \mathrm{Cr}=2, \mathrm{Ni}=3, \mathrm{Cu}=5$, and $\mathrm{Pb}=5$ (Hakanson, 1980)), $C_{i j}$ is the measured concentration $(\mathrm{mg} / \mathrm{kg})$ of the metal of

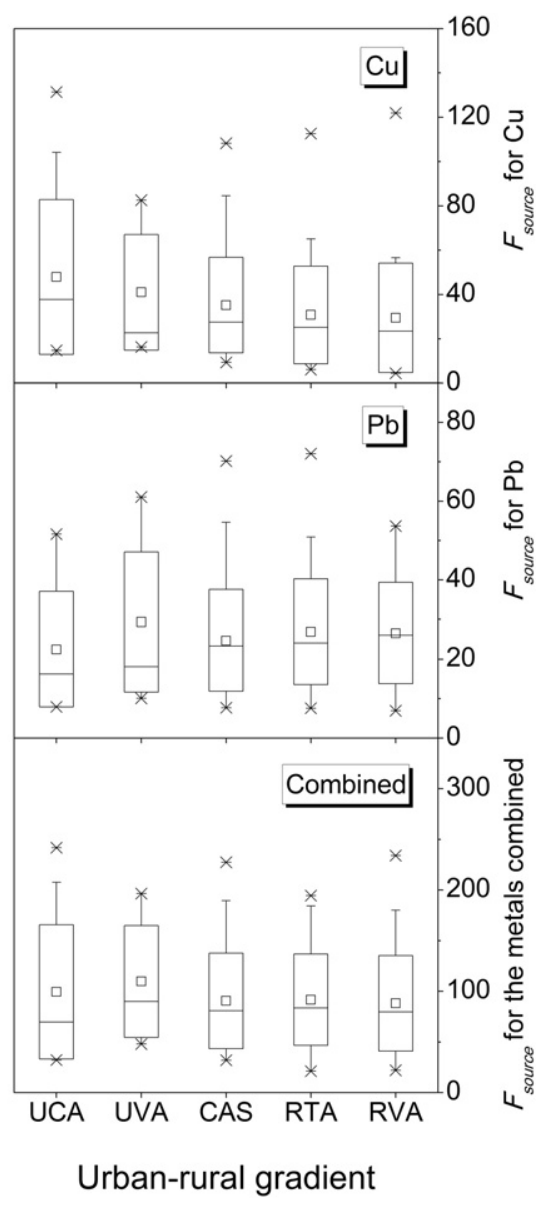

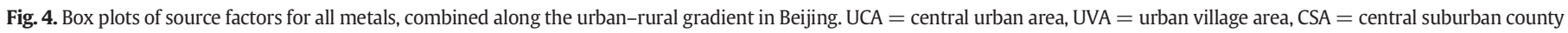
area, $\mathrm{RTA}=$ rural town area, and RVA $=$ rural village area. 
Table 3

Road dust grain size response factors used to assess the potential for particles to become airborne by wind.

\begin{tabular}{|c|c|c|c|}
\hline \multirow[t]{2}{*}{ Response factor } & \multicolumn{3}{|c|}{ Grain size fraction of road dust } \\
\hline & $<44 \mu \mathrm{m}$ & $44-62 \mu \mathrm{m}$ & $62-105 \mu \mathrm{m}$ \\
\hline Particle diameter $(d, m)^{\mathrm{a}}$ & $22 \times 10^{-6}$ & $53 \times 10^{-6}$ & $83.5 \times 10^{-6}$ \\
\hline Threshold friction velocity $\left(u_{* t}(d), \mathrm{m} / \mathrm{s}\right)^{\mathrm{b}}$ & 0.368 & 0.232 & 0.185 \\
\hline Defining the mobility potential $\left(1 /\left(u_{* t}(d)\right)^{2}\right)^{\mathrm{c}}$ & 7.384 & 18.579 & 29.218 \\
\hline Levels ( $\left.F_{\text {transport }}\right)$ defined for road dust mobility ${ }^{\mathrm{d}}$ & 0.253 & 0.636 & 1.000 \\
\hline
\end{tabular}

a The middle particle diameter was used to represent the road dust particle range when calculating $u_{* t}(d)$.

b $u_{* t}(d)$ values were calculated according to the wind erosion threshold friction velocity (Shao and Lu, 2000).

c Particle mobilities are inversely related to $u_{* t}$ values. The mobility potential was defined as $1 /\left(u_{* t}(d)\right)^{2}$, because $u_{* t}^{2}$ is a measure of energy.

d The assignment method was to give the maximum value a value of 1 and express the other values as multiples of that value.

interest $i$ in the road dust with grain size $j, n$ is the number of metals of interest, $m$ is the number of grain size fractions, and $C_{r i}$ is the concentration of the metal of interest in background soil (31.1, 19.7, 27.9, 25.1, and $59.6 \mathrm{mg} / \mathrm{kg}$ for $\mathrm{Cr}, \mathrm{Cu}, \mathrm{Ni}, \mathrm{Pb}$, and $\mathrm{Zn}$, respectively) (Chen et al., $2004), P_{j}$ is the amount of road dust with grain size $j$, expressed as a percentage of total road dust mass, and $M_{\text {weighted }}$ is the bulk road dust mass per unit area at each sampling site.

\subsubsection{Calculating the transport factor}

The mobility of a particular size of road dust particle was estimated using the threshold friction velocity $\left(u_{*}\right)$, which is the minimum friction velocity required for wind erosion to occur (Shao and Lu, 2000). The Shao and Lu scheme estimates the theoretical value for a dry and smooth surface, and it is a function of an idealized particle size under ideal conditions. For a real surface (often wet and rough if the particles

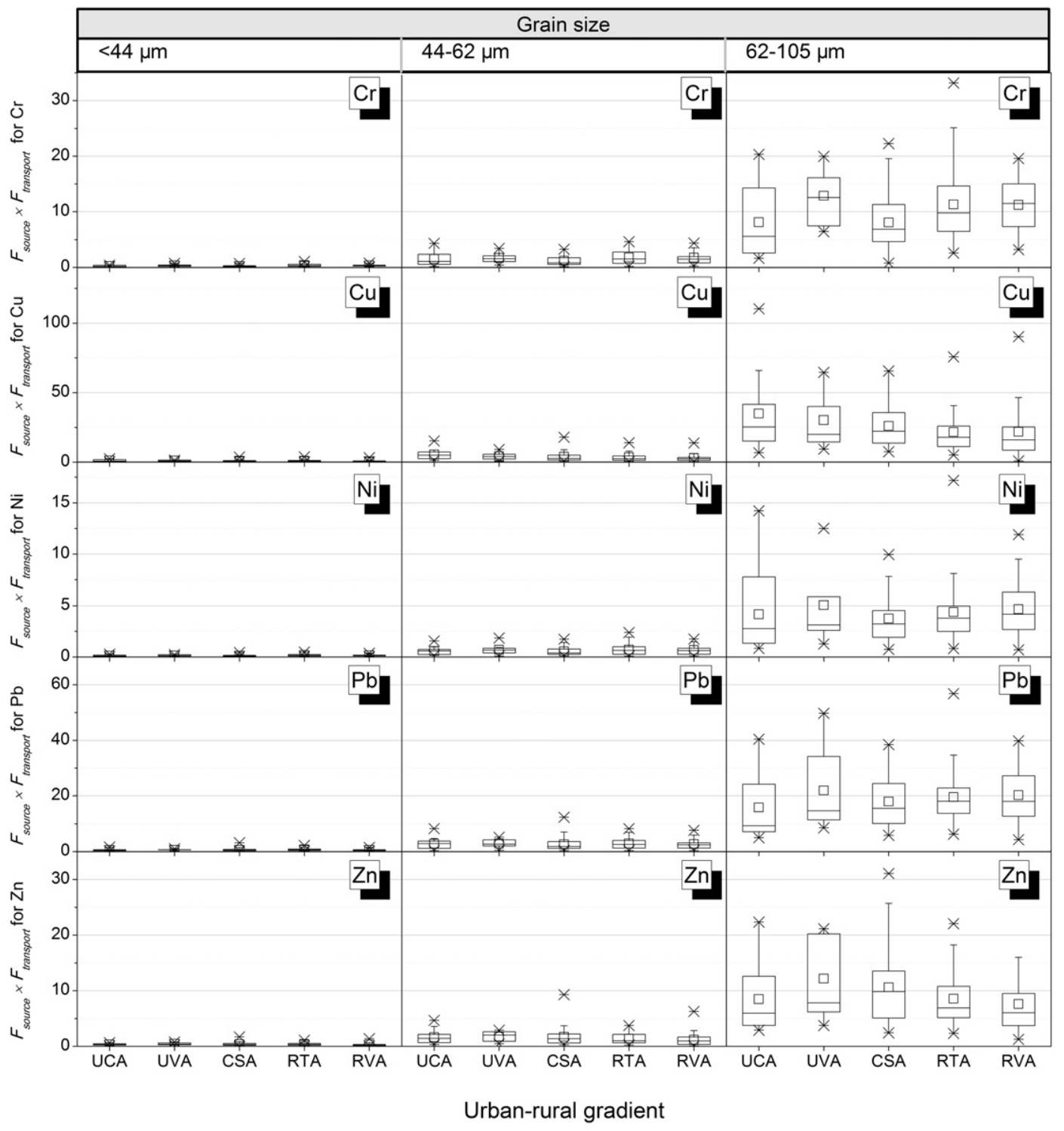

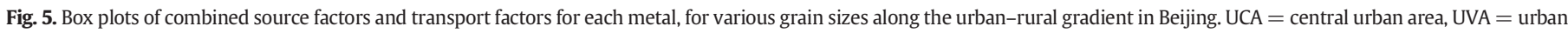
village area, $\mathrm{CSA}=$ central suburban county area, $\mathrm{RTA}=$ rural town area, and RVA $=$ rural village area 

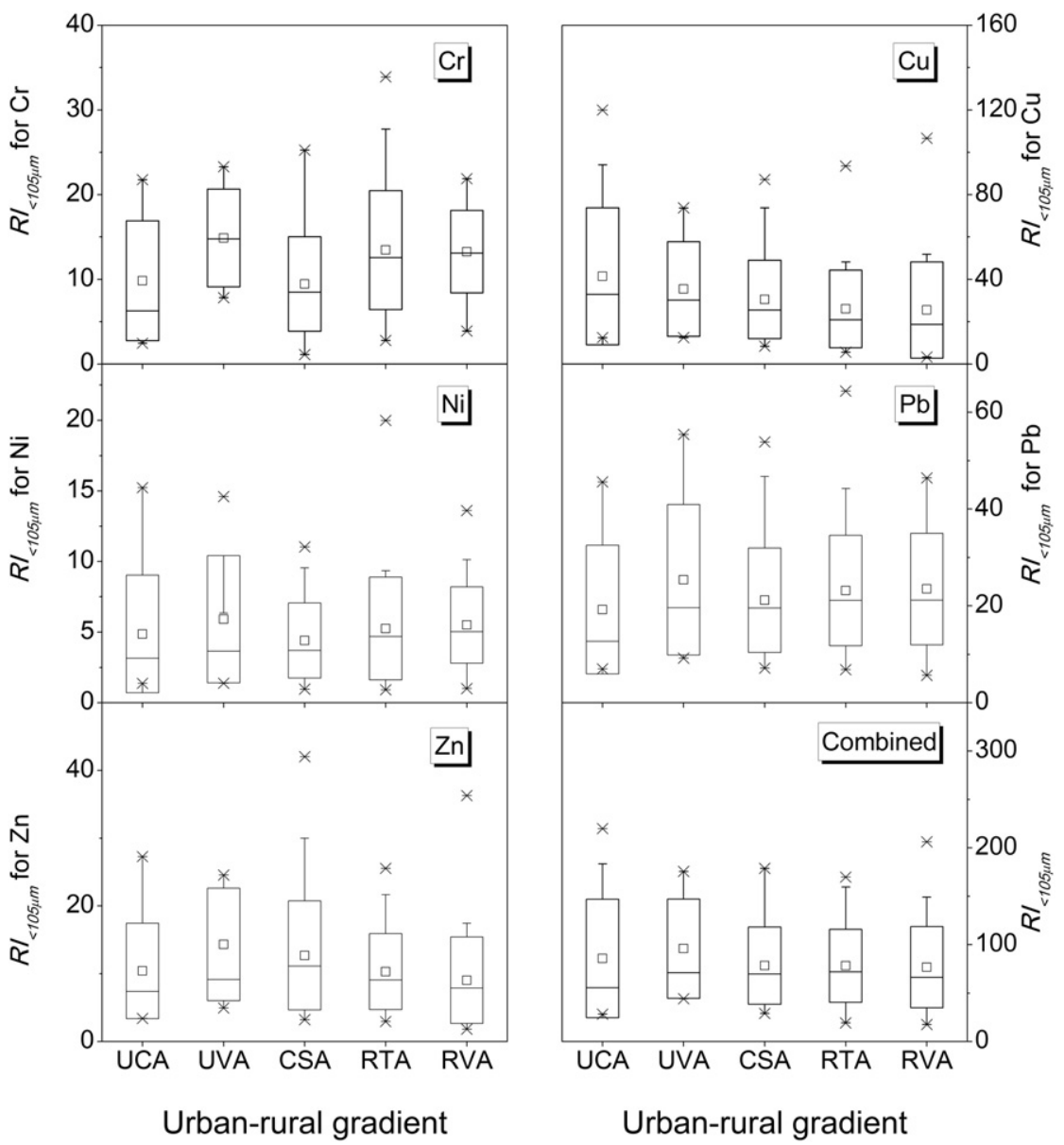

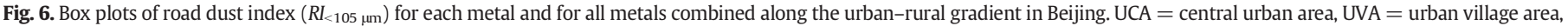
$\mathrm{CSA}=$ central suburban county area, RTA = rural town area, and RVA = rural village area.

contain salt), $u_{* t}$ will be large. We assumed that road dust particles are spherical, smooth, and not deformable, and then calculated particle mobility for each grain size according to $u_{* t}$. We calculated $u_{* t}$ using

$u_{* t}=\sqrt{A_{N}\left(\sigma_{p} g d+\frac{\gamma}{\rho \mathrm{d}}\right)}$,

where $u_{* t}$ is in $\mathrm{m} / \mathrm{s}, A_{N}$ is a constant (0.0123), $\gamma$ was determined empirically $\left(3 \times 10^{-4} \mathrm{~kg} / \mathrm{s}^{2}\right), g$ is the acceleration of gravity $\left(9.81 \mathrm{~m} / \mathrm{s}^{2}\right), d$ is the spherical particle diameter $(\mathrm{m}), \rho$ is air density $\left(1.29 \mathrm{~kg} / \mathrm{m}^{3}\right), \sigma_{p}$ is the particle density to air density ratio (2054, using particle density = $2650 \mathrm{~kg} / \mathrm{m}^{3}$ and air density $\left.=1.29 \mathrm{~kg} / \mathrm{m}^{3}\right)$.

Eq. (3) can also be expressed as Eq. (4) (Shao and Lu, 2000),

$u_{* t}=\sqrt{Y_{1} d+Y_{2} \frac{1}{d}}$

where $Y_{1}$ and $Y_{2}$ are empirical constants and $d$ is particle diameter $(\mathrm{m})$. $Y_{1}$ is $247.84 \mathrm{~m}^{0.5} / \mathrm{s}^{2}$ and $Y_{2}$ is $2.326 \times 10^{-4} \mathrm{~m}^{1.5} / \mathrm{s}^{2}$.

The particle mobility is inversely related to the $u_{* t}$ value. In other words, a larger $u_{* t}$ means that the particle is potentially less mobile.

Table 4

Contributions of road dust particles to atmospheric particulate pollution through resuspension in Beijing and other cities around the world.

\begin{tabular}{|c|c|c|c|c|c|c|}
\hline City & $\begin{array}{l}\text { Road dust } \\
\text { particle }\end{array}$ & $\begin{array}{l}\text { Atmospheric } \\
\text { particle }\end{array}$ & Methods & $\begin{array}{l}\text { Contribution ratio (\%) } \\
\text { or others }\end{array}$ & Pollutants & References \\
\hline Las Vegas, USA & $\mathrm{N} / \mathrm{A}^{\mathrm{a}}$ & $\mathrm{PM}_{10}$ & $\begin{array}{l}\text { Testing re-entrained aerosol kinetic } \\
\text { emissions from roads (TRAKER) }\end{array}$ & $50 \% \mathrm{PM}_{10}$ & & Kuhns et al., 2001 \\
\hline Barcelona, Spain & $\mathrm{N} / \mathrm{A}$ & $\mathrm{PM}_{10} ; \mathrm{PM}_{2.5} ; \mathrm{PM}_{1.0}$ & Positive matrix factorization (PMF) & $17 \% \mathrm{PM}_{10} ; 8 \% \mathrm{PM}_{2.5} ; 2 \% \mathrm{PM}_{1.0}$ & Metals; C & Amato et al., 2009a \\
\hline $\begin{array}{l}\text { Zurich and Reiden, } \\
\text { Switzerland }\end{array}$ & $\mathrm{N} / \mathrm{A}$ & $\mathrm{PM}_{10}$ & PMF & $56 \% \mathrm{PM}_{10}$ & Metals & Bukowiecki et al., 2010 \\
\hline Madrid, Spain & $\mathrm{N} / \mathrm{A}$ & $\mathrm{PM}_{10}$ & PMF & $29 \% \mathrm{PM}_{10}$ & Metals; S; N, C & Karanasiou et al., 2011 \\
\hline Rome, Italy & $\mathrm{N} / \mathrm{A}$ & $\mathrm{PM}_{10}$ & Instrumental nuclear activation analysis (INAA) & & Metals & Avino et al., 2014 \\
\hline Beijing, China & $\mathrm{N} / \mathrm{A}$ & $\mathrm{PM}_{2.5}$ & PMF & $9 \% \mathrm{PM}_{2.5}$ & Metals; C & Song et al., 2006 \\
\hline Beijing, China & $\mathrm{N} / \mathrm{A}$ & TSP, $\mathrm{PM}_{10} ; \mathrm{PM}_{2.5}$ & AP-42 emission factor model & 130 kg/(km d) $P_{10}$ & & Fan et al., 2007 \\
\hline Beijing, China & $<75 \mu \mathrm{m}$ & $\mathrm{PM}_{10} ; \mathrm{PM}_{2.5}$ & $\begin{array}{l}\text { Road dust resuspension simulation } \\
\text { using a small-scale powder disperser }\end{array}$ & $16 \% \mathrm{PM}_{10} ; 19 \% \mathrm{PM}_{2.5}$ & Metals; C & Chen et al., 2012 \\
\hline Beijing, China & $<105 \mu \mathrm{m}$ & $<105 \mu \mathrm{m}$ & $\begin{array}{l}\text { Road dust index (wind erosion threshold } \\
\text { friction velocity) }\end{array}$ & Risk strength & Metals & This article \\
\hline
\end{tabular}

a $\mathrm{N} / \mathrm{A}$ : not available. 
The potential mobilities of particles (PMP) can therefore be ranked according to $1 / u_{* t}^{2}$ (because $u_{* t}^{2}$ is a measure of energy) using defined levels, as shown in Eqs. (5) and (6),

$$
\begin{aligned}
& P M P=\frac{1}{\left(u_{* t}\right)^{2}}, \\
& F_{\text {transport }}=P M P_{\text {weighted }},
\end{aligned}
$$

where $P M P$ is the road dust mobility potential, $P M P_{\text {weighted }}$ is the weighting assigned to PMP, and $F_{\text {transport }}$ and $u_{* t}$ have the same meanings as described for Eqs. (1) and (3).

\section{Results}

\subsection{Variations in road dust characteristics along urban-rural gradient}

The characteristics of road dust particles (e.g., number of particles, grain sizes, and concentrations of metals in the particles) have important impacts on the source and transport factors in the road dust index. This was investigated along the urban-rural gradient in the Beijing metropolitan region. The mass of road dust per unit area clearly varied along that gradient, with low masses per unit area found in the UCA $\left(9.5 \pm 7.6 \mathrm{~g} / \mathrm{m}^{2}\right)$ and CSA $\left(14.2 \pm 13.1 \mathrm{~g} / \mathrm{m}^{2}\right)$, medium masses per unit area in the RTA $\left(28.0 \pm 31.3 \mathrm{~g} / \mathrm{m}^{2}\right)$, and high masses per unit area in the UVA $\left(44.9 \pm 53.7 \mathrm{~g} / \mathrm{m}^{2}\right)$ and RVA $\left(67.0 \pm 73.0 \mathrm{~g} / \mathrm{m}^{2}\right)$ (Fig. 1$)$. This can be attributed to the difference of street cleaning methods and frequencies between urban areas (UCA and CSA) and rural area (RTA, RVA and UVA).

The concentrations of metals in the road dust samples collected along the urban-rural gradient are shown in Fig. 2. Mean $\mathrm{Cr}, \mathrm{Cu}, \mathrm{Pb}$, and $\mathrm{Zn}$ concentrations (i.e., excluding Ni concentrations) in the road dust samples across Beijing were approximately 2-10 times higher than background concentrations of the metals in soil from Beijing (Chen et al., 2004). Mean total concentrations of the analyzed metals decreased along the urban-rural gradient in the order $\mathrm{UCA}>\mathrm{CSA}>\mathrm{UVA}>\mathrm{RTA}>\mathrm{RVA}$. Zn was the most abundant metal in the road dust in all areas.

\subsection{Dividing source factors into levels}

The source factors $\left(F_{\text {source }}\right)$ used in the road dust index included the amount of road dust, grain sizes of the road dust particles, and amounts and types of pollutants associated with those particles. The amount of road dust per unit area was divided into levels, primarily defined using the results of our in situ measurements, because no standard levels have been defined. We had to use a large number of measurements (a total of 164 sites along the urban-rural gradient) to attain satisfactory estimates of the road dust parameters. The mass of road dust per unit area was divided into six levels $\left(M_{\text {weighted }}\right)$, as shown in Table 2 . The numbers of sampling sites in the types of area with values at various levels are also shown in that table. We assigned comparatively small values to high masses of road dust per unit area, because less risk is posed by metals in coarser particles (because metal contents are lower and the metals are less mobile) than by those in finer particles.

Grain sizes of the road dust particles and amounts and types of metals associated with those particles have important effects on $F_{\text {source }}$. The metals associated with road dust were ranked by comparing metal concentrations found in road dust with background concentrations of the metals (Fig. 2). $F_{\text {source }}$ values calculated for each metal with different grain sizes along the urban-rural gradient in Beijing are shown in Fig. 3. The road dust particles with grain sizes $62-105 \mu \mathrm{m}$ had larger values than did the other size fractions for all five metals, indicating that 62 to $105 \mu \mathrm{m}$ particles contributed more than the other particles to $F_{\text {source. }}$. Source factors for all metals combined in the road dust particles with grain sizes $<105 \mu \mathrm{m}$ are shown in Fig. 4 . Mean $F_{\text {source }}$ values for the metals at all sites along the urban-rural gradient decreased in the order $\mathrm{Cu}(36.9 \pm 24.5)>\mathrm{Pb}(26.0 \pm 13.3)>\mathrm{Cr}(14.1 \pm 7.0)>\mathrm{Zn}$ $(13.4 \pm 8.3)>\mathrm{Ni}(5.5 \pm 3.6) . F_{\text {source }}$ values were larger for $\mathrm{Cu}$ and $\mathrm{Pb}$ than for the other metals, because Hakanson (1980) assigned higher toxic response factors to $\mathrm{Cu}$ and $\mathrm{Pb}$ than to the other metals. Mean $F_{\text {source }}$ values for all metals combined in the various areas along the urbanrural gradient decreased in the order UVA $(110 \pm 55)>$ UCA $(100 \pm$ $66)>\operatorname{RTA}(92 \pm 45)>\operatorname{CSA}(91 \pm 47)>\operatorname{RVA}(88 \pm 47)$.

\subsection{Determining transport factors}

To assess the effect of the urban-rural gradient on the potential contribution of road dust to atmospheric particulate pollution along that gradient, the mobility of each road dust particle size fraction must be determined. The transport factors (particle mobilities) for the various road dust grain size fractions, calculated using $u_{*}$, are shown in Table 3. The results show that the finer road dust particles had larger $u_{* t}$ values, indicating that coarser road dust particles could easily be picked up by wind, thereby possibly causing air pollution.

No published standard methods are available for assessing road dust transport factors to allow the different levels to be allocated. We defined PMP using $1 /\left(u_{*}\right)^{2}$ and used PMP to represent the potential for road dust to cause atmospheric particulate pollution, which affects the road dust index. Finally, the $F_{\text {transport }}$ levels were defined according the weightings assigned to PMP, and then we used $F_{\text {transport }}$ for each road dust grain size to calculate the PMP of the bulk road dust in each sampling area.

The $F_{\text {transport }}$ and $F_{\text {source }}$ values were summed, and the combined factors are shown in Fig. 5. The combined factor for the various grain size fractions was designed to be variable, because of variability in $F_{\text {transport }}$. The combined factor for road dust particles with grain sizes 62-105 $\mu \mathrm{m}$ was approximately seven times larger than for those with grain sizes $<44 \mu \mathrm{m}$, and it was $\sim 20$ times larger than for those with grain sizes $44-62 \mu \mathrm{m}$. These results indicate that the main road dust particles becoming resuspended at the theoretical $u_{* t}$ values were those with grain sizes $62-105 \mu \mathrm{m}$.

3.4. Potential risks posed by metals in atmospheric particulates derived from road dust

The road dust index presented here provides a new way of estimating potential risks posed by metals in atmospheric particulate derived from road dust along the urban-rural gradient. The road dust indices for each metal and for all the metals combined are shown in Fig. 6 . The mean $R I_{<105 \mu \mathrm{m}}$ for different areas along the gradient varied in different ways for each metal, indicating that the risks posed by the metals varied in different ways along the gradient.

The $R I_{<105 \mu \mathrm{m}}$ for all metals combined in the different areas decreased in the order UVA $(96 \pm 51)>\operatorname{UCA}(86 \pm 61)>\operatorname{CSA}(78 \pm 40) \approx \mathrm{RTA}$ $(78 \pm 38)>\operatorname{RVA}(77 \pm 42)$, which was slightly different than the order for $F_{\text {source. }}$. This indicated that $F_{\text {source }}$ was more important than $F_{\text {transport }}$ in determining the order for $R I_{<105 \mu \mathrm{m}}$ values along the urbanrural gradient. Our results will help improve understanding of the risks posed by metal pollutants associated with urban atmospheric particulates derived from road dust.

\section{Discussion}

\subsection{Contribution of road dust particles to atmospheric particulate pollution}

The contribution of road dust particles to atmospheric particulate pollution through resuspension has been studied in many cities around the world (Table 4), and such particles have been found to contribute 16-56\% and 8-19\% to $\mathrm{PM}_{10}$ and $\mathrm{PM}_{2.5}$, respectively (Amato et al., 2009a; Avino et al., 2014; Bukowiecki et al., 2010; Chen et al., 2012; 
Fan et al., 2007; Karanasiou et al., 2011; Kuhns et al., 2001; Song et al., 2006). However, the amounts of various pollutants in resuspended road dust have been assessed in very few studies, and this severely hampers the ability to reliably assess the acute impacts of atmospheric particulate pollution. In particular, little information is available on spatial and temporal variations of potential emission sources, and on the mechanisms through which fine road dust particles are resuspended. The new road dust index $\left(R I_{<105 \mu \mathrm{m}}\right)$ was used to estimate the contributions of road dust particles to atmospheric particulate pollution in different areas along the urban-rural gradient. We found that the urban village area (UVA) had highest values of $R I_{<105 \mu \mathrm{m}}$, which was a combination effect of road dust amount, metal concentration and potential motilities. Our investigation indicated that these areas in UVA and RVA were seldom swept (0.2-0.3 times/d), had a high proportion of bare soil, and had broken and rough road surfaces. These factors above resulted in the highest dust particle load in UVA and RVA among the five urban-rural gradient units (Fig. 1). Furthermore, pollution sources such as industrial processes and vehicle emissions in urban areas were much more than those in rural areas (CSA, RTA and RVA), which was reflected in the higher metal concentrations in UVA and UCA (Fig. 2). The combination effects of the factors above result in the highest values of $R I_{<105 \mu \mathrm{m}}$ in UVA.

\subsection{Further considerations for road dust index}

There are still no index models specifically designed for identifying risks posed by road dust. In this study, we developed a road dust index based on the phosphorus index that is used to rank diffuse pollution risks in agricultural areas (Heathwaite et al., 2005; Sharpley et al., 2008), but there remain many deficiencies in this index. The road dust index cannot be directly verified using measured values, because the index cannot be measured. A key point is that the transport factor used in the index was mainly derived from the $u_{* t}$ defined by Shao and Lu (2000). Further work will be needed to identify differences between theoretical road dust particle resuspension rates (under idealized conditions) and actual rates. For real surfaces (wet and rough, if particles contain salt), $u_{* t}$ will be large (Shao and Lu, 2000). We need to modify some of the functions in future studies to achieve this. The transport factor was calculated using the minimum friction velocity required for wind erosion to occur. The road dust index will be almost entirely determined by the source factor when the wind speed is greater than a certain value $(0.368 \mathrm{~m} / \mathrm{s}$ in our calculations, as shown in Table 3$)$. Further studies will be required to provide more quantitative estimates of emissions of road dust particles via resuspension.

\section{Conclusions}

We developed a road dust index model and used it to assess the potential for road dust particles with diameters $<105 \mu \mathrm{m}$ to contribute to atmospheric particulate pollution, using data from different types of areas (UCA, UVA, CSA, RTA, and RVA) in Beijing. The road dust index $\left(R I_{<105 \mu \mathrm{m}}\right)$ varied with area type along an urban-rural gradient, decreasing along main roads along that gradient in the order UVA (96 \pm $51)>\operatorname{UCA}(86 \pm 61)>\operatorname{CSA}(78 \pm 40) \approx \operatorname{RTA}(78 \pm 38)>\operatorname{RVA}(77 \pm$ 42). Variations in the $R I_{<105 \mu \mathrm{m}}$ did not simply match those in the amounts of road dust present or in metal concentrations in the road dust along the urban-rural gradient. The road dust index is a new tool for assessing pollution caused by resuspension of fine road dust particles, and it will help in the management and control of this pollution source.

\section{Acknowledgments}

This study was financially supported by the National Natural Science Foundation of China $(41471417,41171395)$ and the Key Program of the CAS (No.KZZD-EW-10-02).

\section{References}

Amato, F., Pandolfi, M., Escrig, A., Querol, X., Alastuey, A., Pey, J., et al., 2009a. Quantifying road dust resuspension in urban environment by multilinear engine: a comparison with PMF2. Atmos. Environ. 43, 2770-2780.

Amato, F., Pandolfi, M., Viana, M., Querol, X., Alastuey, A., Moreno, T., 2009b. Spatial and chemical patterns of $\mathrm{PM}_{10}$ in road dust deposited in urban environment. Atmos. Environ. 43, 1650-1659.

Avino, P., Capannesi, G., Rosada, A., 2014. Source identification of inorganic airborne particle fraction $\left(\mathrm{PM}_{10}\right)$ at ultratrace levels by means of INAA short irradiation. Environ. Sci. Pollut. Res. 21, 4527-4538.

Bukowiecki, N., Lienemann, P., Hill, M., Furger, M., Richard, A., Amato, F., et al., 2010. PM $_{10}$ emission factors for non-exhaust particles generated by road traffic in an urban street canyon and along a freeway in Switzerland. Atmos. Environ. 44, 2330-2340.

Charlesworth, S., De Miguel, E., Ordóñez, A., 2011. A review of the distribution of particulate trace elements in urban terrestrial environments and its application to considerations of risk. Environ. Geochem. Health 33, 103-123.

Chen, J., Wang, W., Liu, H., Ren, L., 2012. Determination of road dust loadings and chemical characteristics using resuspension. Environ. Monit. Assess. 184, 1693-1709.

Chen, T.B., Zheng, Y.M., Chen, H., Zheng, G.D., 2004. Background concentrations of soil heavy metals in Beijing. Chin. J. Environ. Sci. 25, 117-122.

Etyemezian, V., Kuhns, H., Gillies, J., Green, M., Pitchford, M., Watson, J., 2003. Vehiclebased road dust emission measurement: I - methods and calibration. Atmos. Environ. 37, 4559-4571.

Fan, S., Tian, G., Li, G., Shao, X., 2007. Emission characteristics of paved roads fugitive dust in Beijing. Chin. J. Environ. Sci. 28, 2396-2399.

Gburek, W.J., Sharpley, A.N., Heathwaite, L., Folmar, G.J., 2000. Phosphorus management at the watershed scale: a modification of the phosphorus index. J. Environ. Qual. 29, 130-144.

Hakanson, L., 1980. An ecological risk index for aquatic pollution control. A sedimentological approach. Water Res. 14, 975-1001.

Heathwaite, A.L., Quinn, P., Hewett, C., 2005. Modelling and managing critical source areas of diffuse pollution from agricultural land using flow connectivity simulation. J. Hydrol. 304, 446-461.

Huang, R.-J., Zhang, Y., Bozzetti, C., Ho, K.-F., Cao, J.-J., Han, Y., et al., 2014. High secondary aerosol contribution to particulate pollution during haze events in China. Nature 514, 218-222.

Karanasiou, A., Moreno, T., Amato, F., Lumbreras, J., Narros, A., Borge, R., et al., 2011. Road dust contribution to PM levels - evaluation of the effectiveness of street washing activities by means of positive matrix factorization. Atmos. Environ. 45, 2193-2201.

Kuhns, H., Etyemezian, V., Landwehr, D., MacDougall, C., Pitchford, M., Green, M., 2001. Testing re-entrained aerosol kinetic emissions from roads (TRAKER): a new approach to infer silt loading on roadways. Atmos. Environ. 35, 2815-2825.

Martuzevicius, D., Kliucininkas, L., Prasauskas, T., Krugly, E., Kauneliene, V., Strandberg, B., 2011. Resuspension of particulate matter and PAHs from street dust. Atmos. Environ. 45, 310-317.

Miguel, E.D., Llamas, J.F., Chacón, E., Mazadiego, L.F., 1999. Sources and pathways of trace elements in urban environments: a multi-elemental qualitative approach. Sci. Total Environ. 235, 355-357.

Rogge, W.F., Hildemann, L.M., Mazurek, M.A., Cass, G.R., Simoneit, B.R., 1993. Sources of fine organic aerosol. 3. Road dust, tire debris, and organometallic brake lining dust: roads as sources and sinks. Environ. Sci. Technol. 27, 1892-1904.

Sabin, L.D., Lim, J.H., Venezia, M.T., Winer, A.M., Schiff, K.C., Stolzenbach, K.D., 2006. Dry deposition and resuspension of particle-associated metals near a freeway in Los Angeles. Atmos. Environ. 40, 7528-7538.

Shao, Y.P., Lu, H., 2000. A simple expression for wind erosion threshold friction velocity. J. Geophys. Res.-Atmos. 105, 437-443.

Sharpley, A.N., Kleinman, P.J.A., Heathwaite, A.L., Gburek, W.J., Weld, J.L., Folmar, G.J., 2008. Integrating contributing areas and indexing phosphorus loss from agricultural watersheds. J. Environ. Qual. 37, 1488-1496.

Song, Y., Zhang, Y., Xie, S., Zeng, L., Zheng, M., Salmon, L.G., et al., 2006. Source apportionment of $\mathrm{PM}_{2.5}$ in Beijing by positive matrix factorization. Atmos. Environ. 40, 7661-7662.

Tessier, A., Campbell, P.G.C., Bisson, M., 1979. Sequential extraction procedure for the speciation of particulate trace metals. Anal. Chem. 51, 844-851.

US-EPA, 2011. Emission factor documentation for AP-42, Sect. 13.2.1, paved roads, Measurement Policy Group, Office of Air Quality Planning and Standards, US Environmental Protection Agency available at: http://www.epa.gov/ttn/chief/ap42/ch13/ bgdocs/b13s0201.pdf (last access: 22 February 2013).

Zhao, H., Li, X., 2013. Understanding the relationship between heavy metals in roaddeposited sediments and washoff particles in urban stormwater using simulated rainfall. J. Hazard. Mater. 246-247, 267-276.

Zhao, N., Lu, X., Chao, S., 2014b. Level and contamination assessment of environmentally sensitive elements in smaller than $100 \mu \mathrm{m}$ street dust particles from Xining, China. Int. J. Environ. Res. Public Health 11, 2536-2549.

Zhao, H., Zhao, J., Yin, C., Li, X., 2014a. Index models to evaluate the potential metal pollution contribution from washoff of road-deposited sediment. Water Res. 59, 71-79.

Zhao, H., Li, X., Wang, X., 2011. Heavy metal contents of road-deposited sediment along the urban-rural gradient around Beijing and its potential contribution to runoff pollution. Environ. Sci. Technol. 45, 7120-7127. 